\title{
Dielectric characteristics of epoxy resin modified with tetraethoxysilane in the millimeter range
}

\author{
(C) Vladimir Yu. Chukhlanov, ${ }^{*+}$ Natalia N. Smirnova, and Kirill V. Smirnov \\ Vladimir State University Named after A.G. and N.G. Stoletovs. Gorkogo St., 87. Vladimir, 600000. Russia. \\ Phone: +7 (4922) 479-619; (4922) 47-97-53.E-mail:vladsilan@mail.ru; smirnovann@list.ru; \\ kirillsmirnov1239@yandex.ru
}

*Supervising author; ${ }^{+}$Corresponding author Keywords: epoxy resin, alkoxysilane, tetraethoxysilane, dielectric properties, composite material, microwave radio range, radio transparency.

\begin{abstract}
In this work, the influence of alkoxysilanes introduced into the epoxy resin was studied. That was done in order to study the possibility of using the obtained binders in composite materials with increased radio transparency in the millimetre microwave radio band.

Determination of the modified epoxy resin dielectric characteristics in the millimetre microwave radio transparency was carried out by the waveguide method. The measuring complex consisted of a precision measuring line P1-31, a tunable generator on a Gann diode (30-38 GHz), a ferrite gate, and a section of a standard-section waveguide. Based on measurements of the minimum position displacement of the standing wave coefficient by known propagation constants, the free-space wavelength $\lambda_{0}$ for a given operating

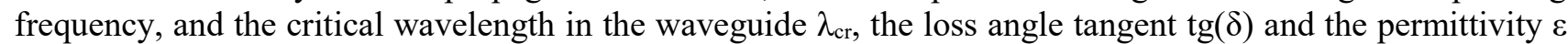
were calculated. Calculations of the permittivity $\varepsilon$, the angle of the dielectric $\operatorname{loss} \operatorname{tg}(\delta)$ and the radio transparency loss- $\Delta \mathrm{P}$ were performed in the MathCad. Moisture absorption of samples was determined by holding them in a desiccator with a humidity of $98 \%$. The samples were kept in a tightly closed desiccator for 24 hours at a temperature of $25{ }^{\circ} \mathrm{C}$. In addition, the relative moisture absorption was determined using the increase in mass.

It was found that the introduction of tetraethoxysilane in the composition in an amount of $1.5-3.5 \%$ leads to a decrease in the tangent of the dielectric loss angle. The optimum is observed in the range of the modifier concentration of $2.5-3.5 \%$. This fact confirms that at these concentrations there is a complete interaction of TEOS alkoxygroups with epoxy resin epoxygroups.
\end{abstract}

\section{References}

[1] N.Yu. Budylin, A.V. Shapagin, R.R. Khasbiullin, and A.E. Chalykh. Miscibility, diffusion and hardening in epoxy oligomer - diaminodiphenyl sulfone system. Butlerov Communications. 2013. Vol.36. No.10. P.107-110. ROI: jbc-02/13-36-10-107

[2] N.N. Smirnova. Interpolyelectrolyte complexation of sulfonate-containing aromatic polyamides in aqueous solutions. Butlerov Communications. 2018. Vol.53. No.2. P.87-93. https://doi.org/10.37952/ROIjbc-02/18-53-2-87

[3] K.A. Medvedeva, and E.N. Cherezova. Study of influence of a new epoxyaminophenol system for service characteristics of polymer-modified cement material. Butlerov Communications. 2018. Vol.53. No.3. P.152-156. https://doi.org/10.37952/ROI-jbc-02/18-53-3-152

[4] V.Yu. Chukhlanov, N.Yu. Nikonova, A.N. Alekssenko.Hydrophobizing liquid for concrete and reinforced concrete structures. Building materials. 2003. No.12. P.38-39. (russian)

[5] V.Yu. Chukhlanov, N.N. Smirnova, N.V. Chukhlanova, and E.E. Mastalygina. Syntactic foams based on hollow ceramic microspheres and binder of oligomethylsilsesquioxane. Butlerov Communications. 2018. Vol.56. No.10. P.107-111. https://doi.org/10.37952/ROI-jbc-02/18-56-10-107 